\title{
The application of MWCNT to enhance the rheological behavior of drilling fluids at high temperature
}

\author{
A. R. Ismail a,b*, W. R. W Sulaiman ${ }^{a, b}$, M. Z. Jaafar ${ }^{a, b}$, A. Aftab ${ }^{a, c}, A$. A. Razi a , Z. H. Ibupoto ${ }^{d}$ \\ a Petroleum Engineering Department, Faculty of Chemical \& Energy Engineering, Universiti Teknologi Malaysia, 81310 Johor Bahru, Malaysia \\ ${ }^{b}$ MPRC-Institute for Oil and Gas, Universiti Teknologi Malaysia, 81310 Johor Bahru, Malaysia \\ c Petroleum and Natural Gas Engineering Department, Mehran UETSZAB Khaipur Mirs, 66020 Sindh Pakistan \\ ${ }^{d}$ Linköping University, Department of Science and Technology (ITN), Linköping, Sweden \\ *Corresponding author: razak@utm.my
}

\section{Article history}

Received 20 May 2016

Accepted 3 August 2016

\section{Graphical abstract}

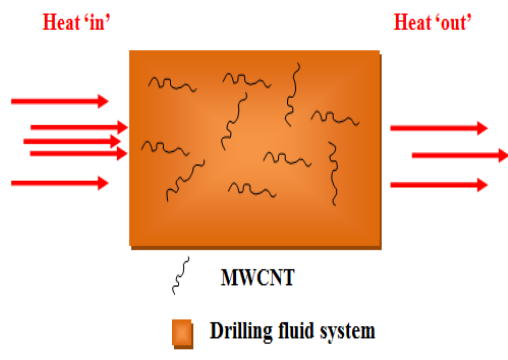

\begin{abstract}
Drilling fluid is the key component to drill oil and gas wells. The rheological behavior of drilling fluid will be affected when drilling deep wells especially at high temperature and high pressure reservoir. This research was conducted to study the effect of the nanoparticles over the rheological properties of the drilling fluid when aging at high temperature condition. Several drilling fluids were prepared using synthetic based fluids (Sarapar and Saraline) to study the effect of multi-walled carbon nanotube (MWCNT) at different concentrations. The rheological properties of drilling fluid were analyzed after aging at $250{ }^{\circ} \mathrm{F}$ and $350^{\circ} \mathrm{F}$ for 16 hours. The results revealed that the addition of MWCNT improved the 10 -sec gel strength by $33 \%$ and filtrate loss volume was reduced to $10 \%$ after aging at $250^{\circ} \mathrm{F}$ in Saraline drilling fluid. Moreover, the plastic viscosity of Saraline and Sarapar drilling fluid after addition of MWCNT was enhanced by $6 \%$ and $27 \%$ at $350{ }^{\circ} \mathrm{F}$. Filtrate loss volume of Sarapar drilling fluid was reduced by $19 \%$ after aging at $250{ }^{\circ} \mathrm{F}$ for 16 hours. The overall results showed that the addition of MWCNT into the drilling fluid have slightly improved the rheological properties of drilling fluids under high temperature conditions.
\end{abstract}

Keywords: Nanoparticle, drilling fluid, rheology, multi-walled carbon nanotube

C 2016 Penerbit UTM Press. All rights reserved

\section{INTRODUCTION}

Drilling fluids are used to facilitate the drilling process by suspending cuttings, controlling bottom hole pressure providing buoyancy, cooling and lubricating the drill bits. It also maintains the stability of the hole and prevents the inflow-outflow of fluids between borehole and the shale formation [1]. As the reservoir is not homogenous, drilling fluid must meet each respective reservoir conditions. There is a factor which is geothermal gradient should be considered in planning drilling fluid program. As a rule of thumb, the change of temperature over depth is $1^{\circ} \mathrm{F}$ per 70 feet. With the drilling of most deep wells, an effective and operational drilling fluid must be tailored that can meet the pressure and temperature condition. Nano fluids, where nano sized particles are added in drilling fluid is considered to be the most effective in combating high temperature condition.

For drilling in a deep well, drilling fluid must have the correct heat transfer and fluid-flow characteristics and must be environmental friendly as well. Over the years, these requirements have been satisfied by both water-based and oil-based fluids. Both contain some form of bentonite clay as well as a number of other additives. For deep-hole drilling, the temperatures and pressures can be excessively high, and the heat transfer demands on the drilling fluid seems impossible to meet [2]. In these circumstances, it become essential to modify a viable drilling fluid which can ensure better thermal properties than the conventional drilling fluid by adding nanoparticles in drilling fluid to stabilize the thermal properties of drilling fluid.
Using nanomaterials to enhance thermal properties of fluids has been subject to many researches since early 1990s. Researchers have investigated the effects of different nanomaterials on thermal properties of liquids, and it can be said that the presence of nanomaterials in a fluid improves thermal characteristics [3].

The nanoparticles in drilling fluids are made of clays and are naturally occurring $1 \mathrm{~nm}$ thick discs of alumino silicates. These nanoparticles exhibit extraordinary rheological properties in water and oil [4]. Recent studies indicates that successful applications of nanotechnology in drilling are likely to occur with synthetic nanoparticles, where size, shape and chemical interactions are carefully controlled to achieve the desired fluid properties and drilling performance [5]. Due to the presence of an astronomical high number of extremely tiny particles with huge surface area, high heat tolerance, high thermal conductivity, high mobility, effective interaction with external and internal rock surfaces, nano-based drilling fluid systems are expected to play a pivotal role in current and future HTHP (high temperature and high pressure) drilling operations, complex drilling conditions, deep water drilling operations, etc [6]. The beyond particles sizes of nanos with their close proximity to the atomic scale compared to macros and micros, the laws that govern nanoscale material behavior are drastically different than the laws governing the macro and micro-scale behavior. The ability to make tailored made particles with custom made behavior is also going to play an important role in superior nano-based fluid formulation. Thus, the application of nano-based fluid additives in formulating high performance water and oil-based drilling fluid systems has the 
potential to overcome the current as well as future technical challenges faced by the oil and gas industry. The extremely high surface area to volume ratio of nanomaterials compared to the macro and micro materials of the same mother source provides them dramatically increased interaction potentials with reactive shale to eliminate shale-drilling fluid interactions and the associated borehole problems. The potential of nanomaterials to form well dispersed plastering effect on the borehole wall with concentration of less than 1 $\mathrm{g}$ in a drilling fluid system is expected to improve the fluid and drilling performance significantly. In the present study, effectiveness of nanomaterial was determined over synthetic based drilling fluid at high temperature aging. Moreover, rheological properties of Sarapar and Saraline based drilling fluid were compared.

\section{EXPERIMENTS}

Laboratory work is carried out as per API 13B-1 recommendations. Synthetic based drilling fluid was prepared by using Sarapar and Saraline fluid for all the tests in this study. Experimental procedure flow chart of present study is shown in Figure 1.

\section{Laboratory mixing procedure}

The basic drilling fluid was prepared and formulated base on 350 $\mathrm{ml}$ scale using Hamilton-Beach mixer. Same additives were used for both Sarapar and Saraline fluid. Sarapar/Saraline oils were placed inside the mixer and Confimul $\mathrm{P}$ were added into the Sarapar or Saraline using a syringe and stirred for 2 minutes followed by addition of Confimul $\mathrm{S}$ and stirred for 5 minutes. Brine were added into the mixer and stirred for another 10 minutes. Configel and Confitrol were added into the system sequentially at intervals of five minutes. Finally, barite were added to the system and stirred for approximately 10 minutes to obtain homogeneous system. The basic synthetic based drilling fluid was further subjected to the addition of Multi-walled Carbon Nanotube (MWCNT) with the concentrations of $0.01,0.05$, and $0.1 \mathrm{~g}$.

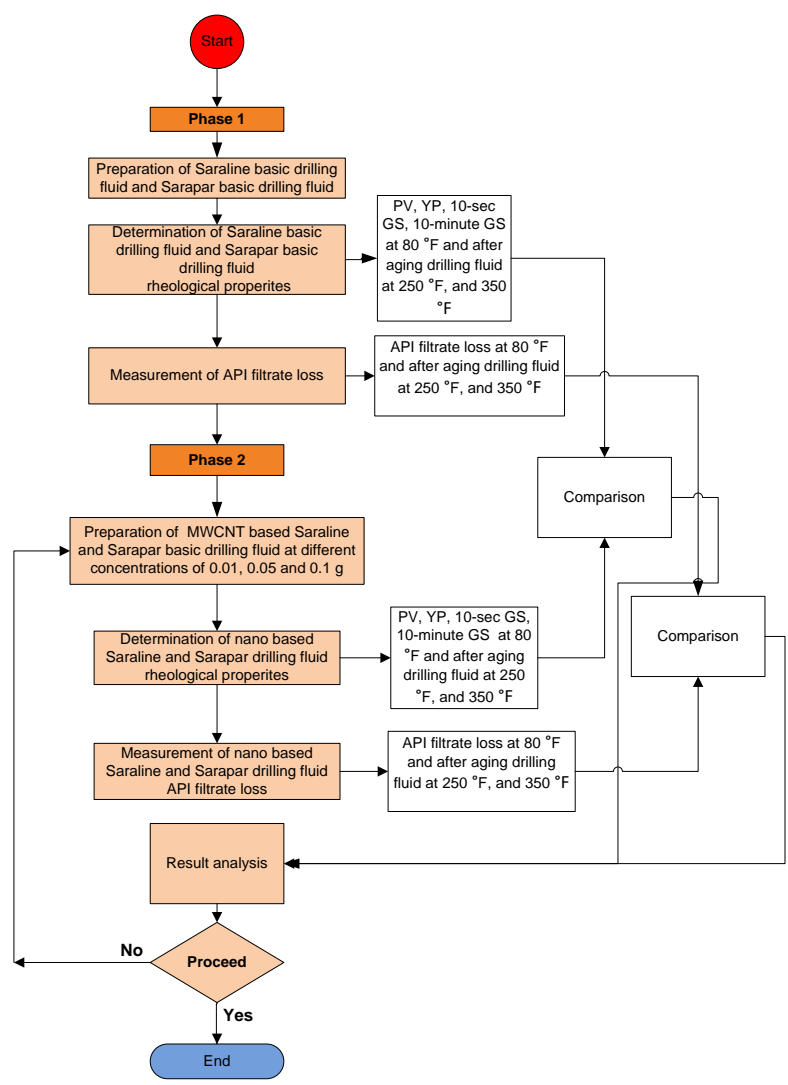

Figure 1 Experimental procedure flow chart.

\section{Drilling fluid test laboratory procedure}

The drilling fluid was tested before hot rolling and after hot rolling for 16 hours at $250{ }^{\circ} \mathrm{F}$ and $350{ }^{\circ} \mathrm{F}$ to simulate the high temperature condition of the reservoir and to see how MWCNT affects the rheology of drilling fluid at high temperature condition. The rheological properties test consists of, plastic viscosity (PV), yield point (YP), gel strength (GS) and filtrate loss (FL). PV and YP were calculated by using equations (1) and (2):

$\mathrm{PV}=\phi 600-\phi 300$

$\mathrm{YP}=\phi_{300}-\mathrm{PV}$

where,

$\phi_{300}=$ dial reading at $300 \mathrm{rpm}$

$\phi_{600}=$ dial reading at $600 \mathrm{rpm}$

\section{RESULTS AND DISCUSSION}

\section{Effect of nanomaterial on plastic viscosity}

It is observed from Figure 2, the little addition of MWCNT increased the plastic viscosity of drilling fluid. The lowest concentration of $0.01 \%$ increased the plastic viscosity for all three temperature condition. So it can be said that the $0.01 \%$ concentration is the optimum concentration. As it is seen, the plastic viscosity increased after the addition of MWCNT at $80{ }^{\circ} \mathrm{F}$ for all three concentrations. PV of basic fluid reduced and reached to $15.5 \mathrm{~Pa} . \mathrm{s}$ at $350{ }^{\circ} \mathrm{F}$, which is below accepting range. MWCNT. However, PV of Saraline fluid slightly increased by using MWCNT at high temperatures.

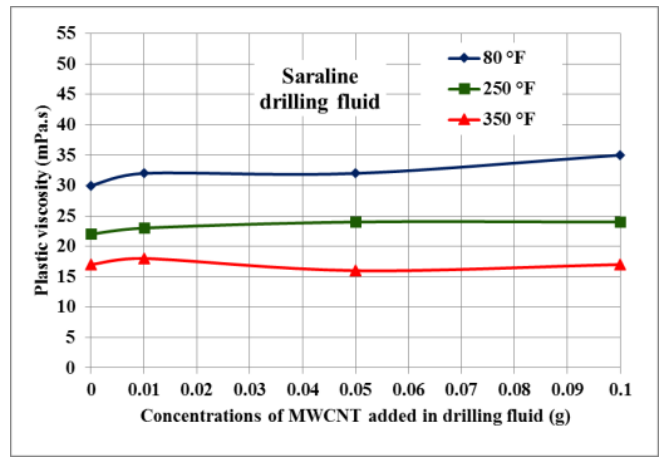

Figure 2 Effect of MWCNT over PV of Saraline based fluid.

The PV of Sarapar based drilling fluid increased gradually with the addition of MWCNT for most of the cases (Figure 3). It is observed that that the optimum concentration of MWCNT for Sarapar is bit higher than Saraline fluid. That means higher concentration of MWCNT is required to increases PV for Sarapar fluid. It is clear from the Figures 1 and 2 that MWCNT can increase the plastic viscosity of both Saraline and Sarapar fluid. However, the plastic viscosity of fluid needs to be optimized for efficient drilling operation.

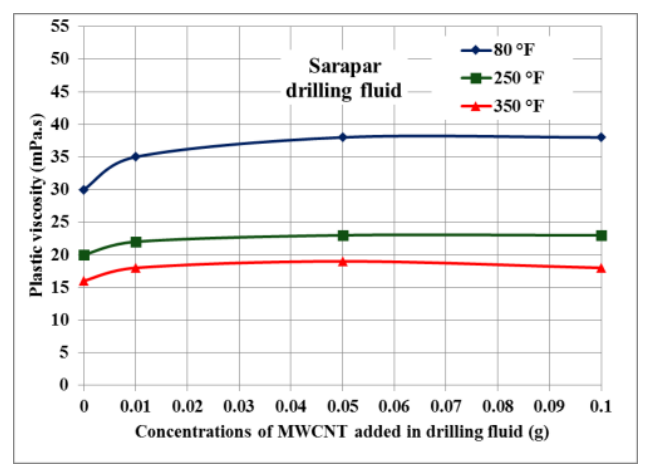

Figure 3 Effect of MWCNT over plastic viscosity of Sarapar base fluid. 


\section{Effect of nanomaterial on yield point}

It is seen from Figure 4 that the multiwall carbon nanotube increased the yield point of Saraline fluid significantly even with the small concentration. The YP for basic Saraline fluid was around 6 Pa.s and it raised to about 10 Pa.s at the highest temperature of 350 ${ }^{\circ} \mathrm{F}$. As MWCNT possesses huge surface area to volume ratio, the addition of MWCNT increases the volume concentration of solid and causes yield point to increase. MWCNT took little time to work on Saraline fluid. It is very clear from the Figure 3 that the fluctuation of YP increased with the increases of temperature. The highest fluctuations observed for the highest temperature of $350^{\circ} \mathrm{F}$.

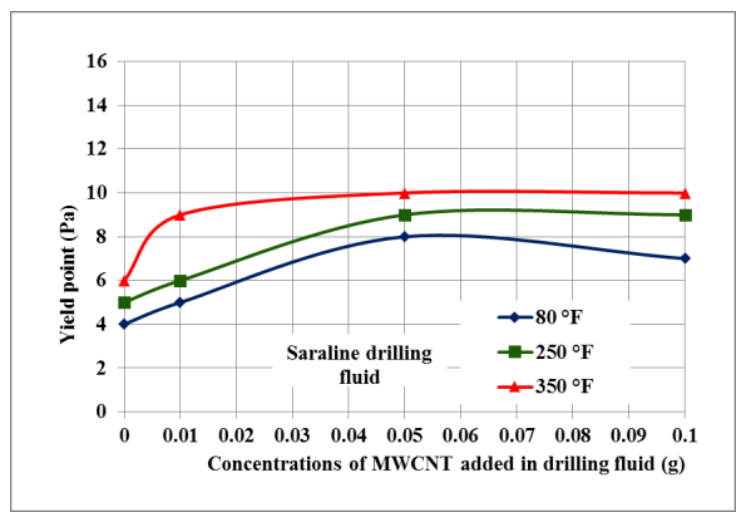

Figure 4 Effect of MWCNT over yield point of Saraline base fluid.

With reference to Figure 5, the addition of MWCNT at $0.01 \mathrm{~g}$ and $0.1 \mathrm{~g}$ increased the YP of Sarapar based fluid gradually for the temperature of $350^{\circ} \mathrm{F}$. It is not desired to have very progressive $\mathrm{YP}$ as it can increase the frictional pressure loss during the circulation of drilling fluid. However, YP of Sarpar fluid at the room temperature incraeses at $0.01 \mathrm{~g}$ and $0.05 \mathrm{~g}$ and decreases at $0.1 \mathrm{~g}$. The reduction of YP can reduce the cutting lifting capacity of drilling fluid. So, the concentration of MWCNT needs to be optimized to provide suitable YP value.

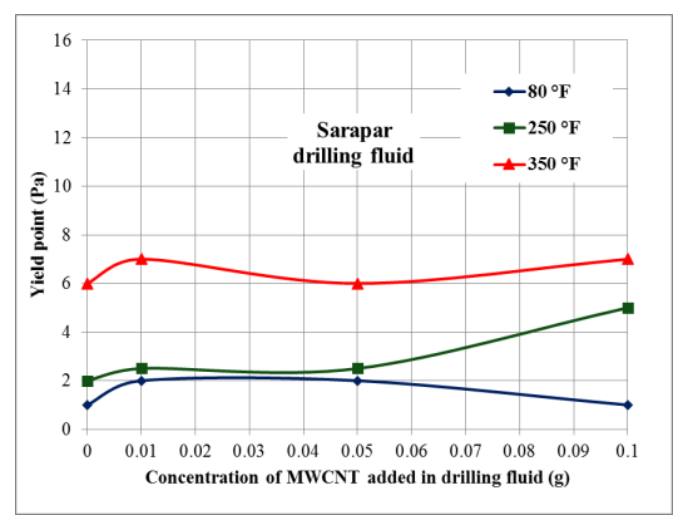

Figure 5 Effect of MWCNT over yield point of Sarapar base fluid.

\section{Effect of nanomaterial on 10-sec gel strength}

10 -sec gel strength is the ability of drilling fluids to suspend drilled material for 10 -sec. In the present study, flat 10 -sec GS rheology was observed. 10-sec GS of basic sarlaline fluid was $2 \mathrm{~Pa}$.s at $350{ }^{\circ} \mathrm{F}$ which is below operating range. Nonetheless, 10-sec GS was raised to $3 \mathrm{~Pa}$.s at $350 \mathrm{~F}^{\circ}$ until $0.1 \mathrm{~g}$ concentration of MWCNT as shown in Figure 6.

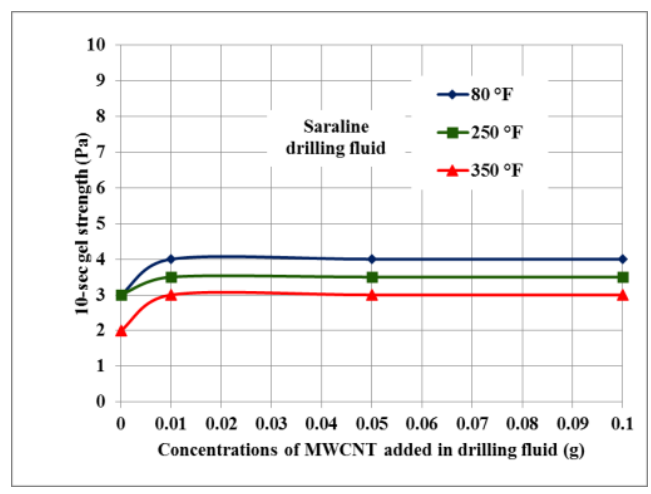

Figure 6 Effect of MWCNT over 10-sec gel strength of Saraline based fluid.

Referring to Figure 7, 10-sec gel strength of Sarapar basic fluid was within operating range at room temperature and $250{ }^{\circ} \mathrm{F}$. However, it was below operating range at $350{ }^{\circ} \mathrm{F}$. Nonetheless, 10 -sec GS was raised to $4 \mathrm{~Pa}$.s with in operating range after addition of $0.1 \mathrm{~g}$ of MWCNT at $350{ }^{\circ} \mathrm{F}$. Moreover, 10-sec and 10-minute GS behavior was found flat after addition of MWCNT.

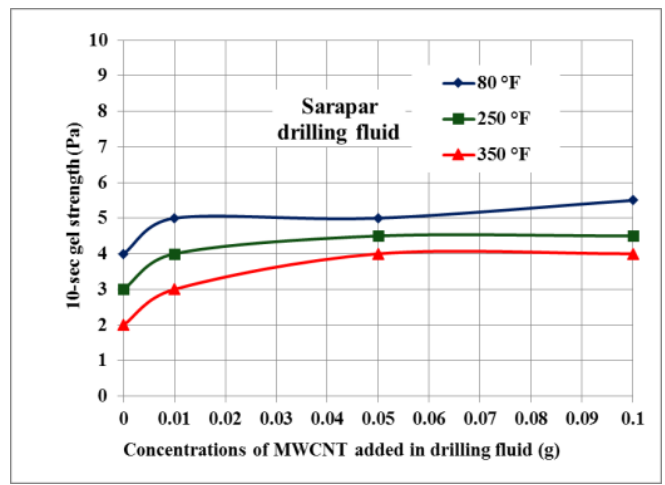

Figure 7 Effect of MWCNT over 10-sec gel strength of Sarapar base fluid.

\section{Effect of nanomaterial on 10-minute gel strength}

10-minute GS was enhanced by the addition of MWCNT in Saraline fluid (Figure 8). However, for both of the conditions, the little concentration of $0.05 \mathrm{~g}$ gave higher 10-minute gel strength than the basic fluid. The addition of MWCNT had a significant effect at $350{ }^{\circ} \mathrm{F}$. There was a gradual increase of gel strength for the concentration of $0.01 \mathrm{~g}, 0.05 \mathrm{~g}$ and $0.1 \mathrm{~g}$.

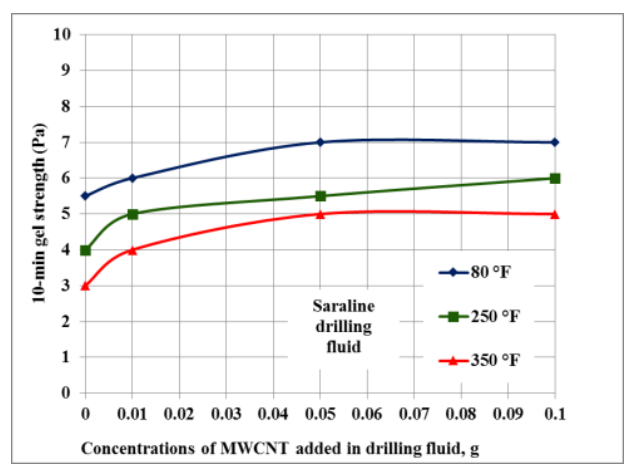

Figure 8 Effect of MWCNT over 10-min gel strength of Saraline base fluid. 
Referring to Figure 9, for all three conditions, the addition of MWCNT increased the gel strength of Sarapar fluid gradually. 10minute GS of Sarapar fluid with MWCNT was above operating range at room temperature. It was reached to below operating range with the increase of temperature. 10-minute GS was achieved with in operating range at $250{ }^{\circ} \mathrm{F}$ and $350{ }^{\circ} \mathrm{F}$ with the addition of MWCNT in Sarapar fluid. GS is need to be maintained with in operating range. High GS fluid required high pumping pressure to lift the fluid from downhole to the surface. Moreover, excessive gel strength increases the need of high pump pressure which may trigger lost circulation and damage the formation badly.

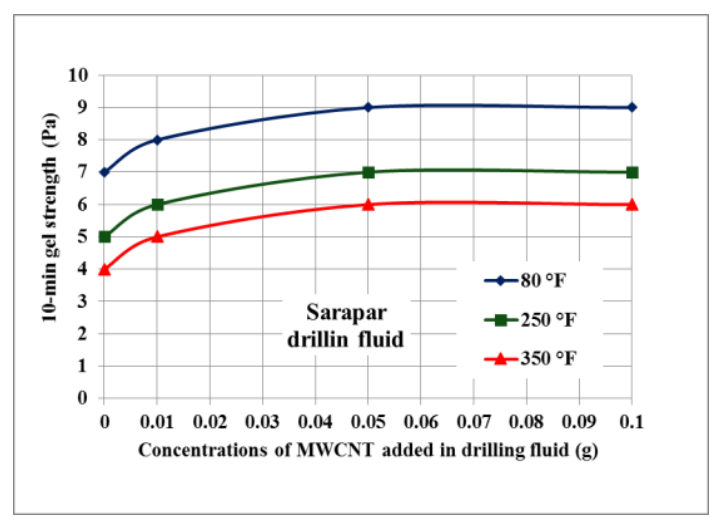

Figure 9 Effect of MWCNT over 10-minute gel strength of the fluid of Sarapar base fluid.

\section{Effect of nanomaterial on filtration loss volume}

The addition of MWCNT slightly reduce the filtrate loss of Saraline fluid at the temperature of $250^{\circ} \mathrm{F}$ and $350{ }^{\circ} \mathrm{F}$ (Figure 10). It is observed that, the fluid loss decreased at room temperature for $0.1 \mathrm{~g}$ of concentration. The fluid particles with MWCNT formed impermeable cake on the filter paper which decreased fluid loss.

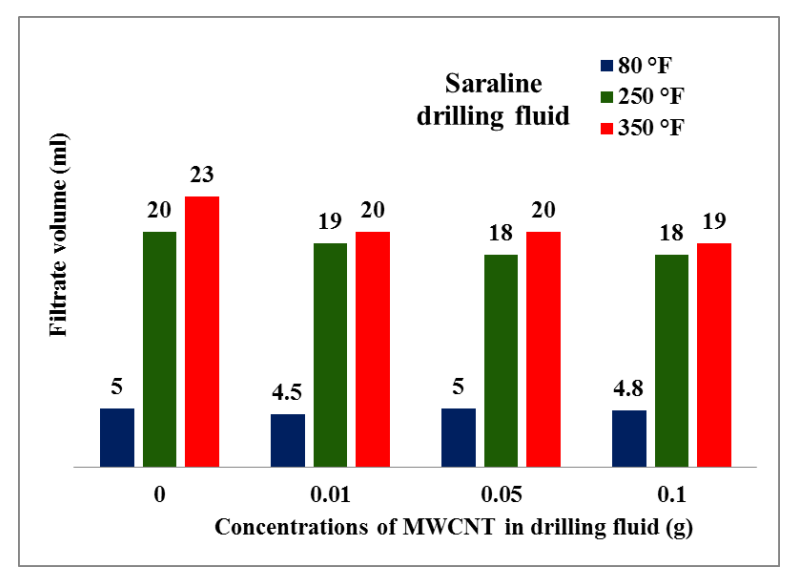

Figure 10 Effect of MWCNT over filtration volume of Saraline base fluid.

Figure 11 shows that MWCNT was found very effective to prevent the filtrate loss after addition of its $0.1 \mathrm{~g}$. Howver, MWCNT slightly reduced filtrate volume at higher temperature.

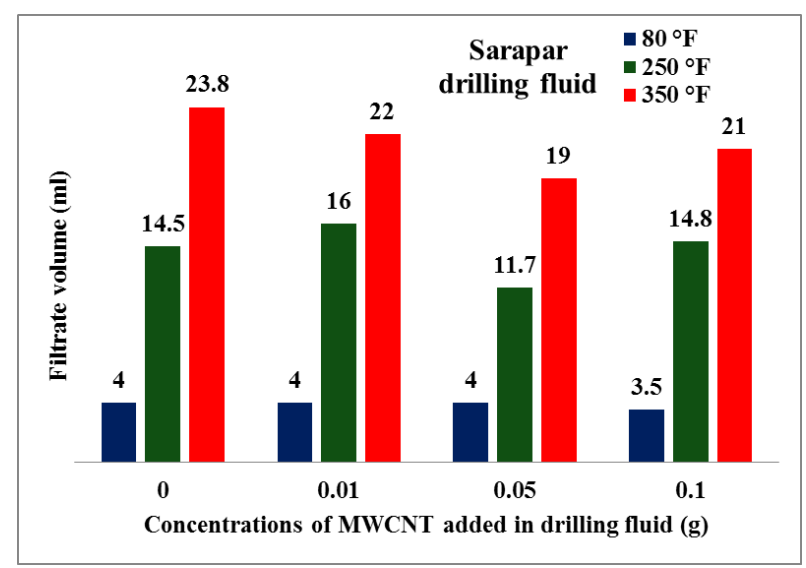

Figure 11 Effect of MWCNT over filtration volume of Sarapar base fluid.

\section{CONCLUSION}

The following conclusions can be drawn from the study:

a) Rheological properties of basic Saraline and Sarapar drilling fluid were not stable at high temperatures.

b) Addition of MWCNT provides better effect over rheological properties of Saraline and Sarapar drilling fluids. Plastic viscosity, yield point and gel strength were improved by using MWCNT at high temperatures.

c) API fluids loss were slightly reduced by using MWCNT at high temperature.

\section{ACKNOWLEDGEMENT}

The authors wish to thank the Ministry of Higher Education, Malaysia and Universiti Teknologi Malaysia for funding this project under Fundamental Research Grant Scheme (vote R.J130000.7842.4F437). The authors also appreciate Scomi Oiltools Sdn. Bhd. for providing the chemicals and additives.

\section{REFERENCES}

[1] Darley, H. C. and Gray, G. R. Composition and Properties of Drilling and Completion Fluids. Houston, Texas, USA. Gulf Professional Publishing (1988)

[2] Agarwal, S., Tran, P., Soong, Y., Martello, D. and Gupta, K. AADE National Technical Conference and Exhibition, 12-14 Apr. 2011, Houston, Texas, USA, 1-6. (2011).

[3] Baghbanzadeh, M., Rashidi, A., Soleimanisalim, A. H. and Rashtchian, D. Thermochimica Acta, 578, 53-58 (2014).

[4] Mokhatab, S., Fresky, M. A. and Islam, M. R. Journal of Petroleum Technology, 58(04), 48-51 (2006).

[5] Amanullah, M., AlArfaj, M. K. and Al-Abdullatif, Z. A. SPE/IADC Drilling Conference and Exhibition, 1-3 March, 2011, Amsterdam, Netherlands, 1-9 (2011).

[6] Singh, S. K., Ahmed, R. M. and Growcock, F. SPE Annual Technical Conference and Exhibition, 19-22 Sept. 2010, Florence, Italy, 1-7 (2010). 